\title{
Aldosterone- and cortisol-cosecreting adrenal adenoma, ovarian hyperthecosis and breast cancer
}

\author{
John J Orrego ${ }^{1}$ and Joseph A Chorny² \\ 'Departments of Endocrinology and Metabolism and 2Pathology, Kaiser Foundation Health Plan of Colorado, Denver, \\ Colorado, USA
}

Correspondence should be addressed to J J Orrego

Email

john.j.orrego@kp.org

\section{Summary}

We describe a 56-year-old postmenopausal woman with hypertension, hypokalemia and severe alopecia who was found to have a 4.5-cm lipid-poor left adrenal mass on CT scan performed to evaluate her chronic right-sided abdominal pain. Hormonal studies revealed unequivocal evidence of primary aldosteronism and subclinical hypercortisolemia of adrenal origin. Although a laparoscopic left adrenalectomy rendered her normotensive, normokalemic and adrenal insufficient for 2.5 years, her alopecia did not improve and she later presented with facial hyperpigmentation acne, worsening hirsutism, clitoromegaly, and an estrogen receptor-positive breast cancer. Further testing demonstrated markedly elevated serum androstenedione and total and free testosterone and persistently undetectable DHEAS levels. As biochemical and radiologic studies ruled out primary adrenal malignancy and obvious ovarian neoplasms, a bilateral salpingo-oophorectomy was undertaken, which revealed bilateral ovarian hyperthecosis. This case highlights how the clinical manifestations associated with hyperaldosteronism and hypercortisolemia masqueraded the hyperandrogenic findings. It was only when her severe alopecia failed to improve after the resolution of hypercortisolism, hyperandrogenic manifestations worsened despite adrenal insufficiency and an estrogen receptor-positive breast cancer was found, did it becomes apparent that her symptoms were due to ovarian hyperthecosis.

\section{Learning points:}

- As cortisol cosecretion appears to be highly prevalent in patients with primary aldosteronism, the term 'Connshing' syndrome has been suggested.

- The associated subclinical hypercortisolemia could be the driver for the increased metabolic alterations seen in patients with Conn syndrome.

- The identification of these dual secretors before adrenal venous sampling could alert the clinician about possible equivocal test results.

- The identification of these dual secretors before unilateral adrenalectomy could avoid unexpected postoperative adrenal crises.

- Hyperfunctioning adrenal and ovarian lesions can coexist, and the clinical manifestations associated with hypercortisolemia can masquerade the hyperandrogenic findings. 


\section{Background}

Adrenal adenomas (AAs) can be discovered serendipitously by radiologic examination in patients evaluated for other reasons or as a result of directed and dedicated adrenal imaging in the setting of adrenal hormone hypersecretion. The latter group, which includes $10-15 \%$ of all AAs, comprises adenomas that produce cortisol, aldosterone, or catecholamines. Although aldosterone- and cortisolcosecreting adrenal adenomas (A/CAAs) were initially thought to be rare, a number of case reports and case series have suggested that this might not be the case $(1,2)$.

Ovarian hyperthecosis $(\mathrm{OH})$, the most common cause of virilization in postmenopausal women, is a nonneoplastic finding characterized by bilateral proliferation of nodular aggregates of luteinized stromal cells with varying amounts of diffuse and variably nested stroma (3). There can be a single dominant $(>0.5 \mathrm{~cm})$ luteinized stromal nodule which has been termed a stromal luteoma, although these are not true neoplasms.

We present here a unique case of a patient with a lipid-poor $\mathrm{A} / \mathrm{CAA}$ and virilizing $\mathrm{OH}$, which although occurring synchronously, were diagnosed 3 years apart as the findings associated with hyperaldosteronism and hypercortisolemia masqueraded the hyperandrogenic manifestations. In the interim, this patient was diagnosed with an estrogen receptor (ER)-positive breast cancer. To our knowledge, this is the first patient reported in the English literature with this combination of lesions.

\section{Case report and treatment}

A 56-year-old African female with chronic rightsided abdominal pain was found to have a left adrenal incidentaloma. An unenhanced adrenal CT scan revealed a $4.5 \times 3.1 \times 3.2 \mathrm{~cm}$ left adrenal mass, with a density of 25 Hounsfield units (Fig. 1). The right adrenal gland was normal. Serum potassium was $3.2 \mathrm{mEq} / \mathrm{L}$ (normal: $3.5-5.0$ $\mathrm{mEq} / \mathrm{L})$ and fasting glucose $(88 \mathrm{mg} / \mathrm{dL})$ and triglycerides (59 $\mathrm{mg} / \mathrm{dL}$ ) were normal. She had been diagnosed with hypertension and hypokalemia 7 years prior to evaluation in our clinic and started on spironolactone and amlodipine. She had had an abdominal hysterectomy at age 42 for uterine fibroids.

In retrospect, she endorsed progressive alopecia for several years that was so severe that she had started wearing a wig 3 years prior to evaluation in our clinic in August 2014. She denied significant weight gain, acne, hirsutism, easy bruisability, or muscle weakness. Blood pressure was 126/78 $\mathrm{mm} \mathrm{Hg}$, weight $96.1 \mathrm{~kg}$, and BMI

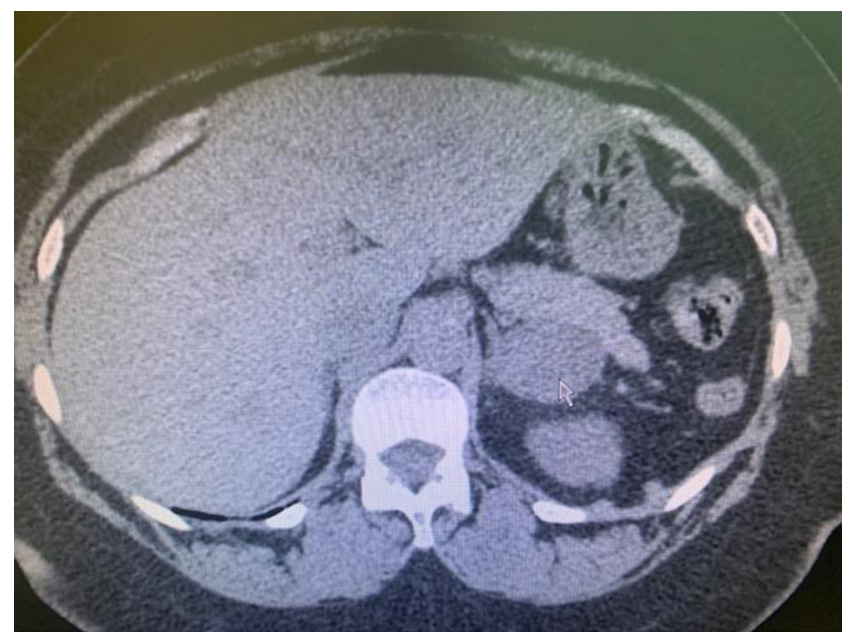

\section{Figure 1}

Left homogeneous adrenal mass with a smooth border on unenhanced CT scan. Tumor calcification and necrosis are absent.

$36.3 \mathrm{~kg} / \mathrm{m}^{2}$. She had generalized obesity, severe diffuse alopecia, and supraclavicular fullness, but no bruising or striae. Given the tumor size, its poor lipid content and the unequivocal dual secretion of cortisol and aldosterone, a left laparoscopic adrenalectomy was performed in January 2015. The surgical specimen revealed a 34 gram, well encapsulated, golden-orange adrenal cortical tumor measuring $4.5 \times 3.5 \times 2.8 \mathrm{~cm}$. Microscopic findings were consistent with an AA (Fig. 2).

In March 2017, she was diagnosed with an invasive ductal breast carcinoma, stage IA, after a screening mammogram. She was treated with lumpectomy and

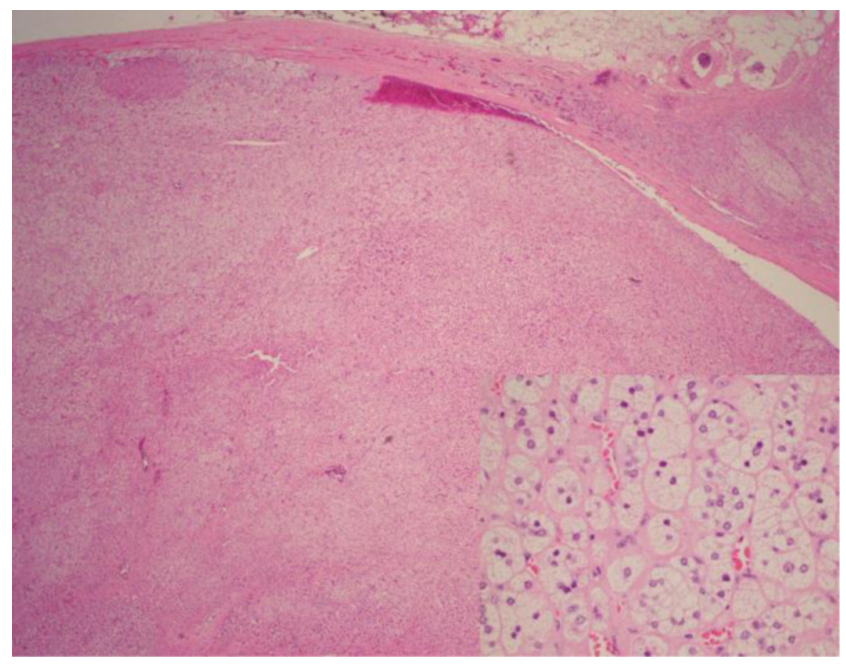

\section{Figure 2}

The adrenal cortical adenoma is well circumscribed and lacks necrosis, atypia and mitotic activity. It is composed of large cells with foamy cytoplasm (H\&E, 20x; inset 400x). 
adjuvant radiation and letrozole. The cancer was ER- and PR (progesterone receptor)-positive, but HER2 (human EGF receptor 2)-negative.

Three months later, while being reevaluated by the endocrinology service, she endorsed persistent alopecia and worsening facial hyperpigmentation acne and hirsutism. Blood pressure was $122 / 70 \mathrm{~mm} \mathrm{Hg}$, weight $98 \mathrm{~kg}$, and BMI $36.9 \mathrm{~kg} / \mathrm{m}^{2}$. Her scalp was still markedly alopecic, there were multiple hyperpigmented facial scars, and her Ferriman $\times$ Gallwey score for hirsutism was 15/36 (normal, <8). Her clitoris was enlarged with otherwise normal external genitalia. Given the ovarian-dependent hyperandrogenemia with negative imaging studies, a laparoscopic bilateral salpingo-oophorectomy (BSO) was undertaken in August 2017. Gross examination revealed that the right and left ovaries measured $3.3 \mathrm{~cm}$ and 3.2 $\mathrm{cm}$, respectively (normal, $2 \mathrm{~cm}$ ). The right ovary had a brown $1.3 \mathrm{~cm}$ well-circumscribed lesion and the left ovary was otherwise unremarkable.

\section{Investigation}

At initial presentation in August 2014, her morning serum cortisol was $18.3 \mu \mathrm{g} / \mathrm{dL}(4-22 \mu \mathrm{g} / \mathrm{dL})$, ACTH $13 \mathrm{pg} / \mathrm{mL} \quad(6-50 \quad \mathrm{pg} / \mathrm{mL})$ and DHEAS $16 \mu \mathrm{g} / \mathrm{dL}$ (35-430 $\mu \mathrm{g} / \mathrm{dL})$. Urine free cortisol was 74 and $77.4 \mu \mathrm{g} /$ day (4-50 $\mu \mathrm{g} / \mathrm{day})$ and 8:00 am serum cortisol was $13.4 \mu \mathrm{g} / \mathrm{dL}$ after $2 \mathrm{mg}$ of dexamethasone taken the night before $(<1.8 \mu \mathrm{g} / \mathrm{dL})$. Urinary metanephrines and catecholamines were normal. While off spironolactone for 6 weeks, her serum potassium was $2.8 \mathrm{mEq} / \mathrm{L}$ (3.5-5.0 mEq/L), renin $0.21 \mathrm{ng} / \mathrm{mL} / \mathrm{h}(0.65-5.0 \mathrm{ng} / \mathrm{mL} / \mathrm{h})$, aldosterone $29 \mathrm{ng} / \mathrm{dL}(\leq 28 \mathrm{ng} / \mathrm{dL})$, and the aldosteroneto-renin ratio was $138(<20)$.

At subsequent presentation in June 2017, her total testosterone was $98 \mathrm{ng} / \mathrm{dL}$ ( $2-45 \mathrm{ng} / \mathrm{dL})$, free testosterone $21.2 \mathrm{pg} / \mathrm{mL}(0.1-6.4 \mathrm{pg} / \mathrm{mL})$, androstenedione $211 \mathrm{ng} /$ dL (20-75 ng/dL), ACTH $23 \mathrm{pg} / \mathrm{mL}$ (6-50 pg/mL), DHEAS $<15 \mu \mathrm{g} / \mathrm{dL}(25-430 \mu \mathrm{g} / \mathrm{dL})$, cortisol $5.6 \mu \mathrm{g} / \mathrm{dL}(4-22 \mu \mathrm{g} /$ $\mathrm{dL})$, and FSH $68 \mathrm{mIU} / \mathrm{mL}(18-153 \mathrm{mIU} / \mathrm{mL})$. Estradiol and LH levels were not obtained. CT imaging revealed no tumor recurrence in the left adrenal bed and her contralateral adrenal gland was unremarkable. A pelvic ultrasound showed that the uterus was absent, the left ovary was not visualized, and the right ovary was normal. Microscopic examination revealed the right nodule to consist of luteinized cells and both ovaries had stromal hyperthecosis consisting of multiple microscopic nodules of luteinized cells (Fig. 3).

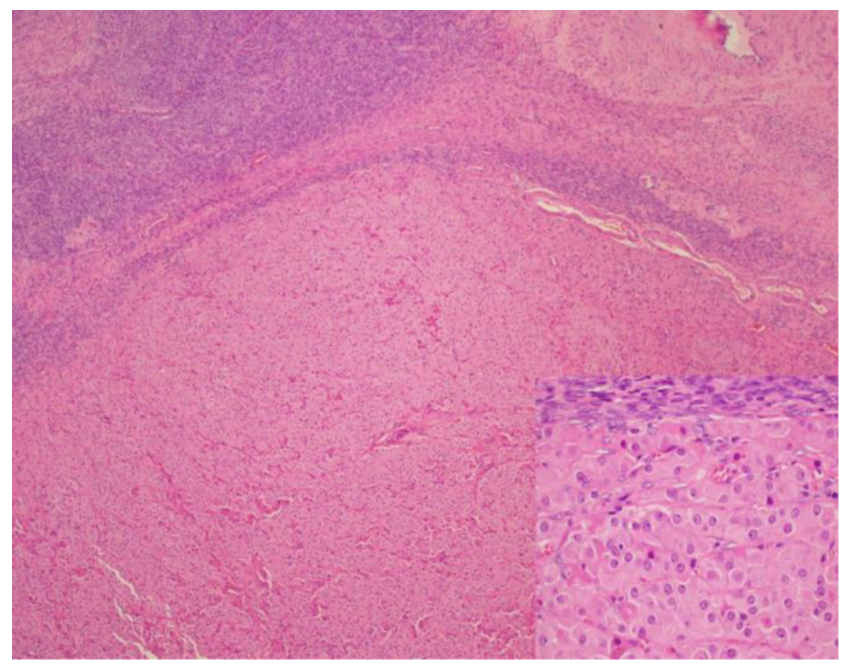

\section{Figure 3}

The right ovary had a dominant stromal luteinize nodule composed of epithelioid cells with abundant eosinophilic cytoplasm surrounding a round vesicular nucleus with a single nucleolus and both ovaries had hyperthecosis with small nests of identical cells. Cystals of Reinke were not identified (H\&E, 40x; inset 400x).

\section{Outcome and follow-up}

Six weeks after left adrenalectomy, and on no medications, her blood pressure $(<120 / 80 \mathrm{~mm} \mathrm{Hg})$, potassium and ACTH levels were normal. She failed an ACTH stimulation test and her DHEAS was $<15 \mu \mathrm{g} / \mathrm{dL}(35-430 \mu \mathrm{g} / \mathrm{dL})$. She required adrenal replacement therapy for 2.5 years.

Three months after BSO, total testosterone was $8 \mathrm{ng} / \mathrm{dL}(14-76 \mathrm{ng} / \mathrm{dL})$ and DHEAS was $<15 \mu \mathrm{g} / \mathrm{dL}$ $(25-430 \mu \mathrm{g} / \mathrm{dL})$. She was lost to follow up soon after.

\section{Discussion}

We describe a unique patient with a lipid-poor A/CAA coexisting with $\mathrm{OH}$ causing virilization and an ER-positive breast cancer.

Although both hormone-producing lesions were likely synchronous at presentation, the symptoms associated with excess androgen secretion by the stromal hyperthecosis were initially missed since all her clinical manifestations were attributed to hyperaldosteronism and hypercortisolemia. Only when her severe alopecia failed to improve after the resolution of the hypercortisolemia and her facial acne and hirsutism worsened despite persistently low levels of DHEAS, it did become apparent that an ovarian source for her hyperandrogenism had to be sought.

Patients with primary aldosteronism (PA) have an increased risk for cardiovascular, renal, and cerebrovascular disease (4). These complications are also more prevalent 
in patients with subclinical or overt hypercortisolemia. Although A/CAAs were initially thought to be rare, recent retrospective series have reported a prevalence of these dual secretors ranging from 5.3 to $21 \%(5,6,7)$. A prospective study evaluating the diagnostic accuracy of postural stimulation testing, CT and adrenal venous sampling (AVS) in the differential diagnosis of PA found that $14 \%$ of the aldosterone-producing adenomas (APAs) also secreted cortisol (8). Subsequently, a steroid metabolome study confirmed that glucocorticoid excess is a frequent finding in PA due to APAs and idiopathic hyperaldosteronism (IHA) and the term 'Connshing syndrome' was proposed for this subgroup of patients (9). These findings suggest that cortisol cosecretion is highly prevalent in patients with PA and it could be the driver for the increased metabolic alterations seen in patients with Conn syndrome (1, 2, 5, 6, 7, 8, 9). More recently, Gerards et al. (10) performed the 1-mg dexamethasone suppression test, late-night salivary cortisol, and 24-h urinary free cortisol in 161 newly diagnosed patients with PA and found that $77.6 \%$ of them had autonomous cortisol secretion as demonstrated by a pathological response in at least one of these screening tests for Cushing's syndrome.

Ovarian androgen-secreting lesions account for $<1 \%$ of ovarian tumors and include hyperthecosis, Leydig cell neoplasms, thecomas, steroid cell tumors, Sertoli cell tumors and some granulosa cell tumors. OH usually consists of bilateral, hyperplastic nests of luteinized cells (3). In some cases, such as the one presented here, there is a grossly distinct larger nodule of luteinized cells, sometimes without smaller nodules. These nodules can be unilateral or bilateral. In the 2003 WHO classification of ovarian sex cord stromal tumors, the dominant nodule was termed a stromal luteoma, but this entity was removed in the 2014 revised WHO classification (11) in favor of the general term stromal hyperthecosis.

$\mathrm{OH}$ accounts for most cases of hirsutism in postmenopausal women. The increased testosterone has been hypothesized to result in increased estradiol by peripheral aromatization in adipose tissue leading to a higher incidence of ER-positive breast cancers (12). This patient was diagnosed with an ER-positive breast cancer which may have been due to an undocumented hyperestrogenic state. This hyperestrogenic state can also be associated with endometrial hyperplasia and carcinoma. Our patient had undergone a hysterectomy 14 years before presentation. Increased testosterone and estrogen are also associated with insulin resistance and testosterone can adversely affect the lipid profile, neither of which were present in this case. It is not clear what causes the insulin resistance in $\mathrm{OH}$ or if it plays a role in its etiology.

Women with virilization from $\mathrm{OH}$ have increased serum testosterone. The bioactive, but not the immunoactive LH level, has been found to be elevated with $\mathrm{OH}$ (13). These patients may respond to treatment with gonadotropin-releasing hormone (GnRH) agonists, which suggests that luteinized cells in $\mathrm{OH}$ are dependent on GnRH and LH (14). In females, LH promotes ovarian follicles to produce estradiol and progesterone while in males it stimulates the Leydig cells to secrete testosterone. This suggests that the LH levels are acting on the luteinized cells to produce testosterone.

Similar to other patients with A/CAAs, our patient is a female (two-thirds of patients are female) in the sixth decade of life (average age is 52 years old) presenting with hypertension, hypokalemia and subclinical hypercortisolemia (only 10\% have overt Cushing's syndrome) in the setting of a unilateral adrenal tumor (more than 90\% harbor a single adenoma) larger than $2 \mathrm{~cm}$ (average tumor size is $2.6 \mathrm{~cm}$ vs $1.5 \mathrm{~cm}$ for APAs) (15). Likewise, most women with $\mathrm{OH}$ are postmenopausal (average age at diagnosis is 61 years old), obese (95\% have a BMI $>30 \mathrm{~kg} / \mathrm{m}^{2}$ ), present with hirsutism and androgenic alopecia, and have multiple and bilateral foci of hyperplastic nests of luteinized cells (14).

Since 2011, five different somatic driver mutations have been found in most patients with APAs. The most common ones are two somatic gain-of-function mutations (G151R or L168R) in the inward rectifier potassium channel KCNJ5 (Kir3.4) which alter the channel's selectivity filter resulting in calcium influx, hyperaldosteronism and cell proliferation, accounting for APA development. In a metaanalysis including 13 studies, the overall prevalence of these mutations in patients with APAs was 43\% (16). APAs with somatic KCNJ5 mutations are usually larger than those without the mutation. Tang et al. (7) found 17 cases with somatic KCNJ5 mutations among 22 patients with A/CAAs.

Recent molecular analyses of some sex chord stromal tumors have revealed genetic aberrations in granulosa cell tumors as well as Sertoli-Leydig cell tumors (17). A somatic mutation in FOXL2, which encodes a transcription factor critically important in the development of granulosa cells, may be associated with granulosa cell tumors. Likewise, DICER1 mutations, which encode an endoribonuclease essential for processing miRNA, are associated with SertoliLeydig cell tumors and other clinical conditions, including pleuropulmonary blastomas and cystic nephromas. $\mathrm{OH}$ has not been found to harbor somatic mutations. 
We found three more case reports of patients with both hyperfunctioning adrenal and ovarian lesions. Two patients presented with concomitant cortisol-secreting AAs and virilizing ovarian Leydig cell tumors $(18,19)$ and one more with a DHEAS-secreting AA and a testosteronesecreting Sertoli-Leydig cell ovarian tumor (20). None of them had breast cancer. To our knowledge, this is the first case report of an A/CAA in a patient with a virilizing $\mathrm{OH}$ and an invasive ER-positive breast cancer.

\section{Declaration of interest}

The authors declare that there is no conflict of interest that could be perceived as prejudicing the impartiality of the research reported.

\section{Funding}

This research did not receive any specific grant from any funding agency in the public, commercial or not-for-profit sector.

\section{Patient consent}

Consent for publication of this study was obtained from the patient.

\section{Author contribution statement}

J J Orrego (endocrinologist) interviewed and examined the patient and ordered all pertinent tests and J A Chorny (pathologist) diagnosed the endocrine lesions. Both contributed to writing the manuscript.

\section{References}

1 Willenberg HS, Spath M, Maser-Gluth C, Engers R, Anlauf M, Dekomien G, Schott M, Schinner S, Cupisti K \& Scherbaum WA. Sporadic solitary aldosterone- and cortisol-co-secreting adenomas: endocrine, histological and genetic findings in a subtype of primary aldosteronism. Hypertension Research 201033 467-472. (https://doi. org/10.1038/hr.2010.18)

2 Yoon V, Heyliger A, Maekawa T, Sasano H, Carrick K, Woodruff S, Rabaglia J, Auchus RJ \& Ghayee HK. Benign adrenal adenomas secreting excess mineralocorticoids and glucocorticoids. Endocrinology, Diabetes and Metabolism Case Reports 20132013 130042. (https://doi.org/10.1530/EDM-13-0042)

3 Sarfati J, Bachelot A, Coussieu C, Meduri G, Touraine P \& Study Group Hyperandrogenism in Postmenopausal Women. Impact of clinical, hormonal, radiological, and immunohistochemical studies on the diagnosis of postmenopausal hyperandrogenism. European Journal of Endocrinology 2011165 779-788. (https://doi.org/10.1530/ EJE-11-0542)

4 Born-Frontsberg E, Reincke M, Rump LC, Hahner S, Diederich S, Lorenz R, Allolio B, Seufert J, Schirpenbach C, Beuschlein F, et al. Cardiovascular and cerebrovascular comorbidities of hypokalemic and normokalemic primary aldosteronism: results of the German Conn's Registry. Journal of Clinical Endocrinology and Metabolism 2009 94 1125-1130. (https://doi.org/10.1210/jc.2008-2116)

5 Piaditis GP, Kaltsas GA, Androulakis II, Gouli A, Makras P, Papadogias D, Dimitriou K, Ragkou D, Markou A, Vamvakidis K, et al. High prevalence of autonomous cortisol and aldosterone secretion from adrenal adenomas. Clinical Endocrinology 200971 772-778. (https://doi.org/10.1111/j.1365-2265.2009.03551.x)

6 Hiraishi K, Yoshimoto T, Tsuchiya K, Minami I, Doi M, Izumiyama H, Sasano H \& Hirata Y. Clinicopathological features of primary aldosteronism associated with subclinical Cushing's syndrome. Endocrine Journal 201158 543-551. (https://doi.org/10.1507/endocrj. k10e-402)

7 Tang L, Li X, Wang B, Ma X, Li H, Gao Y, Gu L, Nie W \& Zhang X. Clinical characteristics of aldosterone- and cortisol-coproducing adrenal adenoma in primary aldosteronism. International Journal of Endocrinology 20182018 4920841. (https://doi. org/10.1155/2018/4920841)

8 Lau JH, Sze WC, Reznek RH, Matson M, Sahdev A, Carpenter R, Berney DM, Akker SA, Chew SL, Grossman AB, et al. A prospective evaluation of postural stimulation testing, computed tomography and adrenal vein sampling in the differential diagnosis of primary aldosteronism. Clinical Endocrinology 201276 182-188. (https://doi. org/10.1111/j.1365-2265.2011.04202.x)

9 Arlt W, Lang K, Sitch AJ, Dietz AS, Rhayem Y, Bancos I, Feuchtinger A, Chortis V, Gilligan LC, Ludwig P, et al. Steroid metabolome analysis reveals prevalent glucocorticoid excess in primary aldosteronism. JCI Insight 20172 e93136. (https://doi. org/10.1172/jci.insight.93136)

10 Gerards J, Heinrich DA, Adolf C, Meisinger C, Rathmann W, Sturm L, Nirschl N, Bidlingmaier M, Beuschlein F, Thorand B, et al. Impaired glucose metabolism in primary aldosteronism is associated with cortisol cosecretion. Journal of Clinical Endocrinology and Metabolism 2019104 3192-3202. (https://doi.org/10.1210/jc.2019-00299)

11 Kurman RJ, Carcangiu ML, Herrington CS \& Young RH (Eds). World Health Organization Classification of Tumours of Female Reproductive Organs, Vol. 6, 4th ed. Lyon: International Agency for Research on Cancer, 2014

12 Secreto G, Girombelli A \& Krogh V. Androgen excess in breast cancer development: implications for prevention and treatment (Review). Endocrine-Related Cancer 201926 R81-R94. (https://doi.org/10.1530/ ERC-18-0429)

13 Nagamani M, Osuampke C \& Kelver ME. Increased bioactive luteinizing hormone levels and bio/immuno ratio in women with hyperthecosis of the ovaries: possible role of hyperinsulinemia. Journal of Clinical Endocrinology and Metabolism 199984 1685-1689. (https://doi.org/10.1210/jcem.84.5.5698)

14 Yance VRV, Marcondes JAM, Rocha MP, Barcellos CRG, Dantas WS, Avila AFA, Baroni RH, Carvalho FM, Hayashida SAY, Mendonca BB, et al. Discriminating between virilizing ovary tumors and ovary hyperthecosis in postmenopausal women: clinical data, hormonal profiles and imaging studies. European Journal of Endocrinology 2017 177 93-102. (https://doi.org/10.1530/EJE-17-0111)

15 Spath M, Korovkin S, Antke C, Anlauf M \& Willemberg HS Aldosterone- and cortisol-co-secreting adrenal tumors: the lost subtype of primary aldosteronism. European Journal of Endocrinology 2011164 447-455. (https://doi.org/10.1530/EJE-10-1070)

16 Lenzini L, Rossitto G, Maiolino G, Letizia C, Funder JW \& Rossi GP. A meta-analysis of somatic KCNJ5 K(+) channel mutations in 1636 patients with an aldosterone-producing adenoma. Journal of Clinical Endocrinology and Metabolism 2015100 E1089-E1095. (https://doi. org/10.1210/jc.2015-2149)

17 Lim D \& Oliva E. Ovarian sex chord-stromal tumours: an update in recent molecular advances. Pathology 201850 178-189. (https://doi. org/10.1016/j.pathol.2017.10.008)

18 Gorgojo JJ, Almodovar F, Lopez E, Vicente del Cerro J, Tejerina E \& Donnay S. Coincidental diagnosis of an occult hilar steroid cell tumor of the ovary and a cortisol-secreting adrenal adenoma in a 49-year-old woman with severe hyperandrogenism. Fertility and Sterility $2003 \mathbf{8 0}$ 1504-1507. (https://doi.org/10.1016/j.fertnstert.2003.05.014)

19 Diab DL, Faiman C, Siperstein AE, Grossman WF, Rabinowitz LO \& Hamrahian AH. Virilizing ovarian Leydig cell tumor in a woman 
Endocrinology

Diabetes \& Metabolism

CASE REPORTS

\section{J J Orrego and J A Chorny}

Adrenal adenoma and ovarian hyperthecosis with subclinical Cushing syndrome. Endocrine Practice 200814 358-361. (https://doi.org/10.4158/ep.14.3.358)

20 Herrera JD, Davidson JA \& Mestman JH. Hyperandrogenism due to a testosterone-secreting Sertoli-Leydig cell tumor associated with a dehydroepiandrosterone sulfate-secreting adrenal adenoma in a postmenopausal woman: case presentation and review of the literature. Endocrine Practice 200915 149-152. (https://doi. org/10.4158/EP.15.2.149)

Received in final form 9 August 2020

Accepted 25 August 2020 